University of Nebraska - Lincoln

DigitalCommons@University of Nebraska - Lincoln

1988

\title{
Kairomonal Stimulation of Oviposition into an Artificial Substrate by the Endoparasitoid Microplitis croceipes (Hymenoptera: Braconidae)
}

R. L. Tilden

Insect Attractants, Behavior, and Basic Biology Research Laboratory, Agricultural Research Service, U.S. Department of Agriculture, Gainesville, Florida

S. M. Ferkovich

Insect Attractants, Behavior, and Basic Biology Research Laboratory, Agricultural Research Service, U.S. Department of Agriculture, Gainesville, Florida

Follow this and additional works at: https://digitalcommons.unl.edu/entomologyother

Part of the Entomology Commons

Tilden, R. L. and Ferkovich, S. M., "Kairomonal Stimulation of Oviposition into an Artificial Substrate by the Endoparasitoid Microplitis croceipes (Hymenoptera: Braconidae)" (1988). Entomology Papers from Other Sources. 111.

https://digitalcommons.unl.edu/entomologyother/111

This Article is brought to you for free and open access by the Entomology Collections, Miscellaneous at DigitalCommons@University of Nebraska - Lincoln. It has been accepted for inclusion in Entomology Papers from Other Sources by an authorized administrator of DigitalCommons@University of Nebraska - Lincoln. 


\title{
Kairomonal Stimulation of Oviposition into an Artificial Substrate by the Endoparasitoid Microplitis croceipes (Hymenoptera: Braconidae) ${ }^{1}$
}

\author{
R. L. TILDEN AND S. M. FERKOVICH
}

Insect Attractants, Behavior, and Basic Biology Research Laboratory, Agricultural Research Service, U.S. Department of Agriculture, Gainesville, Florida 32604

\begin{abstract}
Ann. Entomol. Soc. Am. 81(1): 152-156 (1988)
ABSTRACT Preparation of an artificial oviposition substrate (AOS) from agarose and host hemolymph for oviposition by a parasitic wasp, Microplitis croceipes (Cresson), is described. Natural hosts for this endoparasitoid are larvae of Heliothis spp. Infusion of hemolymph from Heliothis zea (Boddie) into a drop of solidified agar induced females of $M$. croceipes to oviposit into the material. Ovipositional response to dilution of host hemolymph was determined. The factor or factors that stimulated oviposition were moderately heat sensitive, dialyzable, and unaffected by treatment with protease or pancreatic trypsin or hexane extraction. Hemolymph from Manduca sexta (L.) was less effective than $H$. zea hemolymph. The AOS will facilitate in vitro efforts to rear M. croceipes, because dissection of host larvae is no longer necessary and many eggs can be collected easily.
\end{abstract}

KEY WORDS Insecta, Heliothis, Microplitis, oviposition

THE PARASITOID Microplitis croceipes (Cresson) appears to be a good candidate for augmentative releases against larvae of Heliothis zea (Boddie) and $H$. virescens (F.) (Hopper \& King 1984, Stadelbacher et al. 1984). An obstacle to the successful use of this endoparasitoid, however, is the inability to rear the insect at reasonable cost. Development of an artificial medium would be one way to reduce the cost of mass rearing $M$. croceipes, and efforts toward this end have been ongoing (Greany et al. 1984). Once an artificial medium is developed for the insect, a means of collecting large numbers of parasitoid eggs for in vitro culture will be required. We report the presence of an ovipositional kairomone in the hemolymph of $H$. zea larvae and the development of an artificial oviposition substrate (AOS) made from agar drops treated with host hemolymph; the AOS provides the tactile and chemosensory stimuli required to elicit oviposition. This AOS can be used to collect large numbers of eggs for in vitro culture of $M$. croceipes.

Two other parasitoids have been induced to oviposit on surrogate hosts. The pupal parasitoid Itoplectis conquistor (Say) was stimulated to oviposit by hemolymph or selected amino acids such as serine, arginine, and by magnesium chloride placed into parafilm tubes (Arthur et al. 1972). The other parasitoid was an insect egg parasitoid-Rajendram \& Hagen (1974) reported that saline or saline buffers stimulated oviposition of Trichogramma californicum Nagaraja \& Nagarkatti into artificial

\footnotetext{
${ }^{1}$ This article reports the results of research only. Mention of a proprietary product does not constitute an endorsement or a recommendation for its use by USDA.
}

eggs made with wax shells. It was later found that potassium and magnesium were more effective than sodium salts. Lepidopteran eggs have higher concentrations of potassium than of sodium. This im. proved formulation and the synergism between $\mathrm{p} 0$ tassium and magnesium were demonstrated with Trichogramma pretiosum (Riley) (Nettles et al. 1982 , 1983, 1985). Female wasps oviposited into hollow wax spheres that contained a solution of salts, $\mathrm{KCl}$ and $\mathrm{MgSO}_{4}$. Wu \& Qin (1982) reported that Trichogramma dendrolimi (Nagaraja \& Na. garkatti) oviposit in response to the specific amino acids leucine, phenylalanine, and isoleucine.

In this study, the AOS for M. croceipes consisted of agar drops soaked in hemolymph. The active kairomone in hemolymph was partially characterized chemically by physical and enzymatic treatments.

\section{Materials and Methods}

Host and Parasitoid Colony Maintenance. The host species, $H$. zea, was mass reared on pinto beanbased diet as described by Leppla et al. (1982). Manduca sexta (L.) was reared according to Bell et al. (1981). M. croceipes was reared in the laboratory using procedures described previously (Ferkovich \& Dillard 1986). Mated M. croceipes females at least $1 \mathrm{wk}$ old that had been used twice weekly to sting $H$. zea for colony maintenance were used in our experiments.

Preparation of the Artificial Larvae. Agarose (Sigma Scientific) was boiled in water to produce a $0.75 \%$ gel solution. Then, $20-\mu$ l aliquots of aga. 
rose, dispensed with a positive displacement pipet to the surface of Parafilm, formed hemispherical gel drops (AOS).

Hemolymph was obtained from surface-sterilized (70\% ethanol) third- to fifth-instar $H$. zea by expression of 10-30 $\mu \mathrm{l}$ from a proleg of each larva. Approximately $0.1 \mathrm{mg}$ phenylthiourea (PTU) was added to each $100 \mu \mathrm{l}$ of the pooled hemolymph to prevent melanization. Each $20-\mu \mathrm{l}$ gel drop was immersed for at least $20 \mathrm{~min}$ in $20 \mu \mathrm{l}$ of hemolymph. In a similar manner, hemolymph was collected from fifth instars of $M$. sexta for comparison with H. zea hemolymph.

Bioassay Test Conditions. Preference experiments were conducted in plastic Petri dishes $(30$, 60 , or 100 by $15 \mathrm{~mm}$ ). The number of AOS's ranged from 1 to 15 per dish, and the number of female wasps per dish was 1 - or 2 -fold the number of AOS's. Each experiment contained positive controls. Negative controls were used in experiments when indicated. Positive controls contained $\mathrm{H}$. zea hemolymph; the negative control was an AOS prepared with water or phosphate-buffered saline (PBS) $\left(0.8 \% \mathrm{NaCl}\right.$ in $0.05 \mathrm{M} \mathrm{NaH} \mathrm{PO}_{4}$ adjusted to $\mathrm{pH}$ 7.4 with $\mathrm{NaOH}$ ). To minimize different groups of wasps as sources of variation, replicates of each treatment were contained in the same Petri dish as the controls.

Unless otherwise indicated, the time allowed for wasps to sting and oviposit was $1 \mathrm{~h}$ at $24^{\circ} \mathrm{C}$ under fluorescent lighting. The eggs deposited in each agar drop were counted while inverting the dish under a dissecting microscope. The paired Student's $t$ test was used to test for differences between the control and treatment groups (Tassel 1981).

Dilution. Serial dilutions of $H$. zea hemolymph were made with distilled water. Five $20-\mu$ l gel drops were treated for $1 \mathrm{~h}$ with $50 \mu \mathrm{l}$ of each dilution. The undiluted positive control and the water negative control were included with the six diluted samples $(1: 2,1: 4,1: 8,1: 16,1: 32,1: 64)$. The data for five curves were generated from five Petri dishes ( 100 by $15 \mathrm{~mm})$. Each dish contained eight AOS's (two controls and six dilutions of hemolymph) and eight females. After $3 \mathrm{~h}$, the eggs in each AOS were counted. The dose-response relationship was linearized with a log-logit transformation (Berkson 1953) and analyzed by linear regression analysis (Tassel 1981).

Heat Treatment. The bioassay for testing the effects of heat on the ovipositional activity was performed on a split sample of pooled hemolymph collected from $H$. zea fourth and fifth instars. One hundred $\mu$ l of hemolymph was diluted with an equal volume of PBS. Half of the diluted sample was placed in a microfuge tube (Eppendorf) which was placed in boiling water for 5 min. After the heat-denatured sample was centrifuged, the supernatant was compared with the unheated sample by soaking the AOS in each for $30 \mathrm{~min}$. One heattreated and one untreated AOS were placed in each of five Petri dishes ( 30 by $15 \mathrm{~mm}$ ) with four fe- males. There were two replications, with five dishes per replication.

Extraction with Hexane. Twelve AOS's were infused with hemolymph. Six treated AOS's, as well as negative control gels, were extracted with hexane in glass test tubes. The test tubes, each containing three AOS's and $1 \mathrm{ml}$ of hexane, were vortexed four times during $10 \mathrm{~min}$ of extraction. For the bioassay, two Petri dishes ( 100 by $15 \mathrm{~mm}$ ) were used. Each dish contained three replicates (AOS) for each of the four treatments (positive and negative controls, extracted and unextracted) and 12 females.

Dialysis. Cellulose dialysis membranes (BioRad) with a molecular cutoff of 12 kilodaltons $(\mathrm{kD})$ were used. Glycerol and traces of heavy metals were removed from dialysis membranes by boiling with ethylene diamine tetra acetic acid $(1.0 \mathrm{mM}$ EDTA, $2 \% \mathrm{NaHCO}_{3}$ ) prior to use. The moist membrane was supported between two lower halves of Petri dishes ( 35 by $10 \mathrm{~mm})$. Hemolymph $(20 \mu \mathrm{l})$ was placed on a gel drop on the upper surface of a dialysis membrane. A second gel drop was placed on the bottom side of the membrane under the agar drop that was placed on top of the membrane. Twenty min were allowed for the kairomone to diffuse into the lower gel.

The bioassay for testing those hemolymph components that were able to pass through the dialysis membrane was performed as follows. Four AOS's infused with hemolymph on top of the dialysis membrane were placed in one Petri dish ( 30 by 15 $\mathrm{mm}$ ) with eight females. The four AOS's on the bottom side of the dialysis membrane were placed in a second matching Petri dish, also with eight females, for $16 \mathrm{~h}$.

Protease Sensitivity. Hemolymph $(20 \mu \mathrm{l})$ was mixed with $0.5 \mathrm{mg}$ of trypsin or protease (Sigma, bovine pancreatic) and 0.05-0.1 $\mathrm{mg}$ of PTU for 1$3 \mathrm{~h}$ at $24^{\circ} \mathrm{C}$. During the course of several experiments, $1-3 \mathrm{~h}$ was allowed for digestion by protease at $24^{\circ} \mathrm{C}$. The activity of this protease was confirmed by determining that it digested gelatin (Knox). The protease-treated sample was compared to the untreated hemolymph sample by soaking the AOS in each of four replicates of protease-treated hemolymph. Four other AOS's were infused with the same hemolymph source but not subjected to protease activity. Each AOS was placed into one Petri dish ( 30 by $15 \mathrm{~mm}$ ) with two females.

Bioassay of Nonhost, Postemergence Host Hemolymph, and Trehalose. Three tests were conducted in Petri dishes (100 by $15 \mathrm{~mm}$ ). Each dish contained a total of 15 AOS's and 15 females. In one test, the dish contained five AOS's treated with nonhost $M$. sexta hemolymph from fifth instars, five AOS's treated with host $H$. zea hemolymph from fifth instars, and five AOS's with distilled water (negative control). In a second test, five AOS's were treated with nonparasitized host hemolymph from fifth instars, five AOS's with parasitized host hemolymph from fifth instars, and five AOS's with 


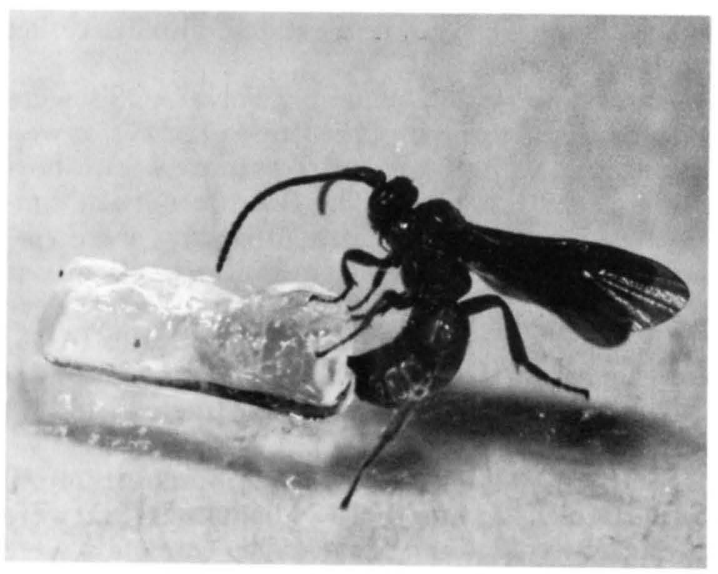

Fig. 1. Photograph of Microplitis croceipes ovipositing into an agarose "larva." The "larva" consists of a $20-\mu \mathrm{l}, 0.75 \%$ agar cylinder soaked in host hemolymph for $20 \mathrm{~min}$.

distilled water. In a third test, five AOS's were treated with fifth-instar host hemolymph after parasitoid emergence, five AOS's with equal parts of $0.5 \mathrm{M}$ trehalose plus postemergence hemolymph, and five AOS's with $0.5 \mathrm{M}$ trehalose alone.

Voucher specimens are on deposit at the Florida State Collection of Arthropods, Gainesville, Fla.

\section{Results}

Insect Behavioral Response to an Artificial Larva. Fig. 1 shows $M$. croceipes ovipositing into a hemolymph-treated artificial oviposition substrate. The shape of the AOS was a 20- $\mu$ l cylinder in preliminary experiments, but a hemispherical shape, also effective, was more easily made by allowing drops of liquid $0.75 \%$ agar to solidify on a plastic surface. It should be noted, however, that the shape of the AOS alone had no effect on the ovipositional response of the females, which were never observed to oviposit into the spheres containing only water (Fig. 2).

Effect of Hemolymph Serial Dilution. Fig. 2 contains the results of one experiment used to determine the effect of diluting $H$. zea hemolymph on the eggs oviposited in AOS by $M$. croceipes during a given time interval $(3 \mathrm{~h})$. At the $1: 8 \mathrm{di}-$ lution, an intermediate response is followed by attenuation at higher dilutions. With water only (infinite dilution), no eggs were oviposited.

For regression analysis, the log of the dilution factor was expressed by the abscissa $(\mathrm{X})$. The mean of five replications for each of the seven dilution treatments was expressed as a percentage $(\mathrm{P})$ of the maximum number of eggs observed in a single AOS. The ordinate $(\mathrm{Y})$ was the logit in this loglogit transformation. The logit of $\mathrm{Y}$ was calculated as a function of $\mathrm{P}, \operatorname{logit}(\mathrm{Y})=\operatorname{Ln}[\mathrm{P} /(100-\mathrm{P})]$. After linear regression analysis (Tassel 1981), the equation $\mathrm{Y}=2.8-1.66 \mathrm{X}$ had a regression coefficient $(R)$ of 0.94 .

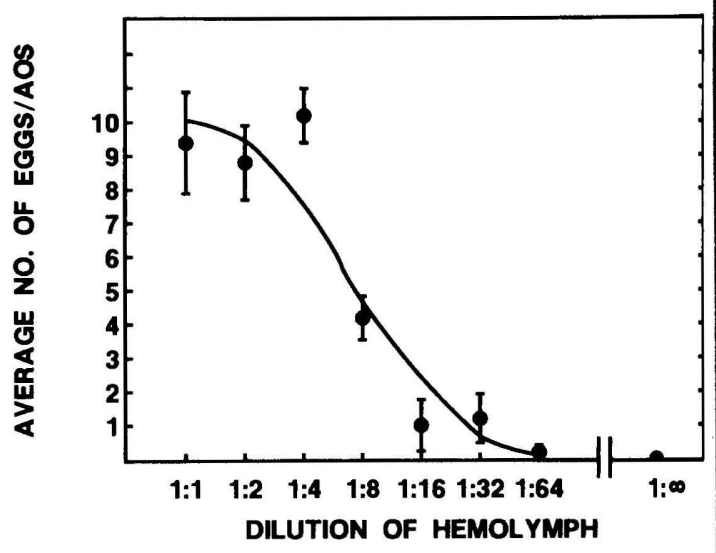

Fig. 2. Effect of $H$. zea hemolymph dilution on $M$. croceipes AOS bioassay activity. Length of bioassay was $3 \mathrm{~h}$. Each open circle represents the mean of five observations for each treatment. Brackets refer to standard error of the mean. The solid line was calculated from the regression of $\log$-logit linearized data.

Properties of the Hemolymph Kairomone. When hemolymph was heated with boiling water for $5 \mathrm{~min}$, some loss of the original activity was observed (Table 1). However, it is likely that this slight loss of activity may have resulted from the binding of some of the stimulant by the precipitate that was removed by centrifugation.

Extraction of hemolymph-treated agar drops with purified hexane had no effect on subsequent ovipositional activity. This suggests that the oviposition-stimulating kairomone was not a lipid.

The kairomone could diffuse through a dialysis membrane with a $12 \mathrm{kD}$ cutoff. Therefore, the molecule is probably polar with a molecular weight of less than 12,000 .

Trypsin and protease had no effect (Table 1); their activity was verified using gelatin as a substrate. Phenylthiourea, included to inhibit phenyl oxidase activity, did not inhibit enzyme activity.

Table 1. Effects of treatments on oviposition activity of $\boldsymbol{H}$. zea hemolymph

\begin{tabular}{lrlrl}
\hline \hline \multirow{2}{*}{$\begin{array}{l}\text { Treat- } \\
\text { ment }\end{array}$} & \multicolumn{4}{c}{ Mean (SD) eggs per AOS } \\
\cline { 2 - 5 } & $n^{b}$ & Control & $n^{b}$ & \multicolumn{1}{c}{ Treated } \\
\hline Heat $^{c}$ & 10 & $3.8(2.3)$ & 10 & $2.1(1.9) \mathrm{S}$ \\
Hexane $^{d}$ & 6 & $7.8(3.6)$ & 6 & $7.0(3.9) \mathrm{NS}$ \\
Dialysis $^{e}$ & 4 & $3.3(2.3)$ & 4 & $2.3(2.6) \mathrm{NS}$ \\
Protease $^{f}$ & 4 & $3.3(3.0)$ & $\mathbf{4}$ & $2.3(0.96) \mathrm{NS}$ \\
\hline
\end{tabular}

${ }^{a}$ Artificial oviposition substrate (AOS) consisting of a drop of $20 \mu$ l solidified agar treated with hemolymph.

${ }^{b}$ Number $(n)$ of AOS's used as a control or as the treated. Significant (S) with one-tailed, paired Student's $t$ test $(P=0.05)$; NS, no significant differences.

${ }^{c}$ Hemolymph heated with boiling water for $5 \mathrm{~min}$.

${ }^{d}$ AOS with hemolymph was incorporated and extracted with $1 \mathrm{ml}$ of purified hexane. No eggs were deposited in negative controls (data not shown); AOS soaked in distilled water and hexane.

$e$ Cellulose dialysis membrane with a mol wt cut-off of 12,000 .

$f$ Digestion of $80 \mu \mathrm{l}$ hemolymph with $0.4 \mathrm{mg}(10 \mathrm{mg} / \mathrm{ml}) \mathrm{pan}$ creatic protease for $1 \mathrm{~h}$ at $24^{\circ} \mathrm{C}$. 
Table 2. Bioassays performed on various sources of hemolymph, including the effects of trehalose synergism on oviposition kairomonal activity in $M$. croceipes

\begin{tabular}{|c|c|c|}
\hline & \multicolumn{2}{|c|}{ No. eggs per $\operatorname{AOS}^{a}$} \\
\hline & $\bar{x}$ & SD \\
\hline \multicolumn{3}{|l|}{ Hemolymph } \\
\hline H. zea & 13.3 & $2.5^{b}$ \\
\hline M. sexta & 2.8 & 3.6 \\
\hline Control (distilled water) & 0.0 & 0.0 \\
\hline \multicolumn{3}{|l|}{ Postemergence hemolymph ${ }^{c}$} \\
\hline Nonparasitized hosts & 8.2 & $6.6^{d}$ \\
\hline Parasitized hosts & 1.8 & 2.6 \\
\hline Control (distilled water) & 0.0 & 0.0 \\
\hline \multicolumn{3}{|l|}{ Trehalose synergism ${ }^{e}$} \\
\hline $\begin{array}{l}\text { Hemolymph of parasitized hosts } \\
\text { and trehalose }\end{array}$ & 5.4 & $2.9^{b}$ \\
\hline Hemolymph of parasitized hosts & 2.0 & $1.2^{b}$ \\
\hline Trehalose & 0.0 & 0.0 \\
\hline \multicolumn{3}{|c|}{$\begin{array}{l}{ }^{a} \text { Artificial oviposition substrate (AOS). } \\
{ }^{b} \text { Significance of difference (one-tailed, unpaired } t \text { test) between } \\
\text { a value and the one directly below it in a column shown at } 0.05 \\
\text { level. } \\
{ }^{c} \text { Postemergence refers to } H \text {. zea hemolymph of fifth instar after } \\
\text { parasite has emerged. } \\
{ }^{d} \text { Significant at } P=0.10 \text {. } \\
{ }^{e} \text { Refers to } H . z e a \text { hemolymph. }\end{array}$} \\
\hline
\end{tabular}

To prevent the effects that enzymes might have on the ovipositor, the positive controls and the treated samples were each held in separate Petri dishes. Results of this experiment did not demonstrate a reduction in the number of eggs per AOS as a result of protease digestion of host hemolymph. These results indicate that the kairomone is probably not a protein or a peptide.

Bioassay of Nonhost and Postemergence Host Hemolymph for Kairomonal Activity. Hemolymph of $M$. sexta, a nonpermissive host for $M$. croceipes, had about $20 \%$ of the activity of $\mathrm{H}$. zea (Table 2). Comparative analysis of those two hemolymphs may provide clues for identification of the kairomone in future work.

Postemergence hemolymph $(\boldsymbol{H}$. zea larvae after parasitoid emergence, in a state of developmental arrest) was much less effective than normal fourthinstar hemolymph. However, when trehalose was added to postemergence hemolymph, much of the activity was restored. Synergism appeared to be operating, for trehalose alone had no activity ( Table 2).

\section{Discussion}

$M$. croceipes is one of only a few hymenopterous parasitoids for which an artificial oviposition substrate has been developed. Our observations suggest that the females obtained information by probing the host's interior with sensillae located on the ovipositor and were responding to an ovipositional kairomone in the hemolymph of the host.

Our preliminary studies into the nature of the oviposition stimulant indicate that it has a molec- ular weight of less than 12,000 and is somewhat heat sensitive, but it is probably not a protein or peptide because trypsin and protease had no effect on activity.

Hemolymph taken from fourth instars of $H$. zea after being parasitized by $M$. croceipes was less effective than hemolymph from nonparasitized larvae. However, addition of trehalose restored much of the activity, indicating a synergistic effect by the sugar. Trehalose had little activity alone as an ovipositional stimulant, but it did increase oviposition of $I$. conquistor when added to solutions of the amino acids serine and arginine (Arthur et al. 1972).

\section{Acknowledgment}

Manuscript reviews by W. Nettles, Jr., D. Dahlman, and P. Landolt are appreciated. We thank Jo-Ann Flemming and F. Eller for their valuable suggestions. P. D. Greany provided advice and shared his interest. C. R. Dillard provided technical support, and Elaine $\mathrm{S}$. Turner typed the manuscript

\section{References Cited}

Arthur, A. P., B. M. Hegdekar \& W. W. Batsch. 1972. A chemically defined, synthetic medium that induces oviposition in the parasite Itoplectis conquisitor ( $\mathrm{Hy}$ menoptera: Ichneumonidae). Can. Entomol. 104: 1251-1258.

Bell, R. A., C. D. Owens, M. Shapiro \& J. R. Tardif. 1981. Development of mass-rearing technology, pp. 599-655. In C. E. Doane \& M. L. McManus [eds.] The gypsy moth: research toward integrated pest management. USDA Technical Bulletin. 1584.

Berkson, J. 1953. A statistically precise and relatively simple method of estimating the bio-assays with quantal response based on the logistic function. J. Am. Statist. Assoc. 48: 565-599.

Ferkovich, S. M. \& C. R. Dillard. 1986. A study of uptake of radiolabeled host proteins and protein synthesis during development of eggs of the endoparasitoid, Microplitis croceipes (Cresson) (Braconidae). Insect Biochem. 16: 337-345.

Greany, P. D., S. B. Vinson \& W. J. Lewis. 1984. Insect parasitoids: finding new opportunities for biological control. BioScience 34: 690-696.

Hopper, K. R. \& E. G. King. 1984. Feeding and movement on cotton of Heliothis species (Lepidoptera: Noctuidae) parasitized by Microplitis croceipes (Hymenoptera: Braconidae). Environ. Entomol. 13: 1654-1660.

Leppla, N. C., W. R. Fisher, J. R. Rye \& C. W. Green. 1982. Lepidopteran mass rearing: an inside view, pp. 123-133. In Sterile insect technique and radiation in insect control. International Atomic Energy Agency Publication No. IAEA-SM-255/14, Vienna, Austria.

Nettles, W. C., Jr., R. K. Morrison, Z. N. Xie, D. Ball, C. A. Shenkir \& S. B. Vinson. 1982. Synergistic action of potassium chloride and magnesium sulfate on parasitoid wasp oviposition. Science 218: 164-166.

1983. Effect of cations, anions and salt concentrations on oviposition by Trichogramma pretiosum in wax eggs. Entomol. Exp. Appl. 33: 283-289. 
1985. Effect of artificial diet media, glucose, protein hydrolysates, and other factors on oviposition in wax eggs by Trichogramma pretiosum. Entomol. Exp. Appl. 38: 121-129.

Raj endram, G. F. \& K. S. Hagen. 1974. Trichogram$m a$ oviposition into artificial substrates. Environ. Entomol. 3: 399-401.

Stadelbacher, J. E., J. E. Powell \& E. G. King. 1984 Parasitism of Heliothis zea and H. virescens (Lepidoptera: Noctuidae) larvae in wild and cultivated host plants in the Delta of Mississippi. Environ. Entomol 13: 1167-1172.

Tassel, D. V. 1981. Basic-peak statistics for small computers. Prentice-Hall, Englewood Cliffs, N.J.

Wu, Z. X. \& J. Qin. 1982. Ovipositional response of Trichogramma dendrolimi to the chemical contents of artificial eggs. Acta Entomol. Sin. 25: 363-372.

Received for publication 12 January 1987; accepted 13 August 1977. 